\title{
Understanding Older Adult's Technology Adoption and Withdrawal for Elderly Care and Education: Mixed Method Analysis from National Survey
}

Ching-Ju Chiu ${ }^{1}$, PhD; Chia-Wen Liu $^{2}$, BS

${ }^{1}$ Institute of Gerontology, College of Medicine, National Cheng Kung University, Tainan, Taiwan

${ }^{2}$ Institute of Physical Therapy, College of Medicine, National Cheng Kung University, Tainan, Taiwan

Corresponding Author:

Ching-Ju Chiu, $\mathrm{PhD}$

Institute of Gerontology, College of Medicine

National Cheng Kung University

No 1, University Road

Tainan, 70101

Taiwan

Phone: 88662353535 ext 5739

Fax: 88663028175

Email: cjchiu@mail.ncku.edu.tw

\section{Abstract}

Background: Elderly adults have comprised the fastest growing population adopting the Internet and computer technology over the past decade. However, how their experiences can shed light on elderly learning theory has not been examined much in the literature.

Objective: This study investigated the factors and reasons associated with Internet adoption and withdrawal among older adults in Taiwan, and if any gender differences exist in this context.

Methods: Data on participants aged 50 years and older from the nationally representative "Digital Opportunity Survey on Individuals and Households in Taiwan," who did not use the Internet in 2005 but adopted it in 2007 (n=1548), and those who reported using Internet in 2011 but then withdrew ( $\mathrm{n}=1575)$, were analyzed. Factors and reasons associated with Internet adoption and withdrawal were examined using both quantitative and qualitative data.

Results: Education level independently predicted Internet adoption behavior. With regard to the reasons for adoption, $66 \%$ (62/94) of participants indicated they started using the Internet to meet certain "needs"; for example, "keeping up with the world" $(40.4 \%, 38 / 94)$ was listed as the most critical reason, followed by "job needs" $(25.5 \%, 24 / 94)$. Older adults with a positive attitude toward the Internet with regard to increasing employment opportunities (OR 2.0, 95\% CI 1.0-3.9, P=.04) and the amount of information obtained (OR 0.5, 95\% CI 0.3-0.9, $P=.01$ ), as well as enriching recreation and entertainment (OR 0.6, 95\% CI 0.4-0.9, $P=.02$ ), were less likely to withdraw from the Internet. The most common reason for Internet withdrawal was "psychological barriers" (eg, no available time, no meaningful use, or nothing worth reading/watching; 66.3\%, 193/291), followed by "health barriers" (eg, eyes or body deteriorate with Internet use; $21.0 \%, 61 / 291$ ). Although psychological barriers were the most important factor for Internet withdrawal for both men $(72.5 \%, 100 / 138)$ and women $(62 \%, 93 / 150)$, women were more likely than men to be affected by health barriers $(26.0 \%, 39 / 150$ vs $15.9 \%, 22 / 138 ; P=.004)$ and anthropic factors or accidental barriers $(7.3 \%$, $11 / 150$ vs $2.9 \%, 4 / 138 ; P=.02)$.

Conclusions: Our findings that the need to keep up with the world associated with Internet adoption, and gender differences in reasons behind Internet withdrawal, such that women reported more health and anthropic factors or accidental barriers than man, may provide a new perspective that help health educators understand strategies that encourage older adults to keep learning, an important component of active aging.

(J Med Internet Res 2017;19(11):e374) doi: 10.2196/jmir.7401

\section{KEYWORDS}

Internet adoption; Internet withdrawal; digital opportunity; information literacy; middle-aged and older adults; Taiwan 


\section{Introduction}

Demographic statistics indicate that $8.1 \%$ of the global population were older adults in 1960, and this number grew to $10 \%$ in 2000 , with estimates suggesting that $21.4 \%$ of the population will be senior citizens in 2050 [1]. A demographic survey in the United States indicated that the elderly population will increase from $13 \%$ in 2010 to $19 \%$ in 2030 [2]. Internet use is increasingly widespread, although the number of people who do not use the Internet frequently, such as the elderly, is in fact increasing [3]. Despite this, the first nationally representative study in the United States showed that the proportion of seniors (those aged 65 years and older; mean 75, SD 7.4 years) who use any digital health technologies significantly increased from $21 \%$ in 2011 to $25 \%$ in 2014 [4].

Internet use can bring many benefits, such as increasing the happiness and decreasing the loneliness of older adults in a retirement community [5], encouraging social connections, and accelerating information exchanges among adults older than 50 years in the United States [6]. Studies have shown that the social functions that come from Internet use contribute to the maintenance of relationships for older adults aged 57 to 87 years [7], particularly for older people with limited mobility, because it is a good way for them to come out of solitude and reconnect to the rest of the world [6]. One of the significant aims of active aging is to keep learning in order to adapt to the changes that occur in later life, gain capabilities similar to those of younger people, and remain productive [8], and it is believed that older adults' involvement in the Internet may achieve this [9-13]. But the Internet is associated with security concerns and learning anxiety (eg, how to handle the operating systems, how to resolve any problems encountered, and the fear that one might break an expensive device) [14,15]. Not every population group benefits from Internet use, and there can even be certain negative impacts. However, many studies in the United States indicate that there are more positive than negative impacts arising from Internet use [16-18].

Many studies have been conducted on why older people may choose to avoid the Internet, such as the webpage design not being suitable for older people and the perception of not being able to learn new things because of insufficient cognitive capability, vision, or motor function [19-27]. The diverse needs of older users should be considered in the design and development of such technology [13]. However, there are still only a handful of studies that aim to understand Internet withdrawal among middle-aged and older adults. A previous study showed that the objective of e-learning was not only to describe something, but also to demonstrate how to do it [28]. Knowles' adult education theory [29] highlights the importance of self-direction, a reservoir of experience, social roles, and problem-centered orientation in affecting adult learning, and Internet adoption and withdrawal may be affected by these factors. For example, the Internet creates an independent learning opportunity for the self-directed learning of adults, while family or friends can serve as a facilitator. Older learners have a large body of experience to serve as a background for new learning, and they are strongly motivated to learn information that has immediate application [30]. In contrast, if adults feel they are unable to learn, they are more likely to withdraw from Internet use.

Gender differences may also exist in Internet adoption and withdrawal among middle-aged and older adults. Previous studies indicated that website attributes [31], Internet usage patterns [32], and habits [33] are different across genders. More males use the Internet than females [32], and the differences in their visual cues have a great impact on their online choices [34]. Women have also expressed greater levels of anxiety toward computers [35], less self-perceived competence, and lower perceived ease of use with respect to the Internet [36] than men. Moreover, older males seem to perceive the Internet as more useful due to their perceived higher levels of ease of use than females [37]. However, some studies found no differences across genders in these respects [38,39]. It is thus an interesting issue whether there are any gender differences in Internet adoption and withdrawal. If we could underline different characteristics associated with gender, it would encourage the development of genuinely usable information and communications technology products, training, and support approaches, and it could be used as a basis for the design of continuing education materials or for market segmentation of men and women.

In Taiwan, there is little data on older adults' Internet use, with no nationwide surveys. As a result, there is no solid reference material for Internet adoption and withdrawal among middle-aged and older adults in Taiwan. In addition, because older adults are the fastest growing population in adopting the Internet and computer technology during the past decade [40], depicting factors and reasons associated with Internet adoption and withdrawal may shed light on some aspects of elderly learning theory. Thus, the purposes of this study were (1) to understand the prevalence of Internet adoption and withdrawal among middle-aged and older adults in Taiwan, (2) to examine the factors associated with Internet adoption and withdrawal among middle-aged and older adults in Taiwan, (3) to identify the reasons behind those who had Internet adoption and withdrawal, and (4) investigate if the aforementioned patterns differed by gender.

\section{Methods}

\section{Study Participants and Data Sources}

Data were derived from an on-going survey, the Individual \& Household Digital Opportunity Survey, approved by the National Development Council in its Research on Constructing the Index System of Digital Opportunity Development in Taiwan. It covers home phone users and interviews native Taiwan citizens aged 12 years or older residing in ordinary households, and it has been carried out every year since 2002 . Computer-assisted telephone interviews were adopted in this survey using a random stratified sampling procedure.

Each year's survey mainly covers information on Internet access, information literacy, information application, digital opportunity, and digital exclusion. Each year's survey is designed as a cross-sectional study of that year. However, only one follow-up survey was conducted, with the first and second surveys taking 
place in 2005 and 2007. Those participants who did not use the Internet in 2005 were asked again in 2007 whether they had done so. As a result, we used the data in 2007 for the issue of Internet adoption. In addition, only the 2011 survey asked a question about Internet withdrawal; therefore, the 2011 survey was selected to examine the issue of Internet withdrawal. A total of 1548 valid participants aged 50 years and older in 2007 (success rate: $72.4 \%$ ) and 1575 adults in 2011 (success rate: $69.4 \%$ ) were analyzed in this study.

\section{Measures}

\section{Sociodemographic Variables}

Age (range 51-94 years), gender, living area (northern, central, southern, and eastern Taiwan and outer islands), economic status (with an income of Taiwanese new dollar [NT\$] NT\$30,000 or less, between NT\$30,000 and NT\$90,000, and NT\$90,000 or more per month), and educational background (elementary school or lower, high school, college or higher) were recorded.

\section{Internet Adoption/Withdrawal}

In this study, those who did not use the Internet in 2005 were asked in 2007 whether they now did. Those who answered "yes" were defined as Internet adopters, whereas those who answered "no" were defined as Internet nonadopters. For Internet withdrawal, the definition was based on the Internet use experience in 2011 and whether the person had used the Internet in the last month. Those who had previous experience of Internet use and had used it in the last month were defined as Internet nonwithdrawers, whereas those who had previous experience of Internet use but had not used it for a month were defined as Internet withdrawers. The reasons for Internet adoption and withdrawal were obtained from an open-ended question. Participants were asked: "Why did you start to use the Internet?" in 2007 and "Why don't you use the Internet anymore?" in 2011.

\section{Opinions on Internet Use}

Opinions on Internet use were divided into three dimensions of "perceived helpfulness," "perceived fun," and "perceived interpersonal interaction." The question for perceived helpfulness was "Is Internet use in your opinion helpful to your life?" and the choices were 1=very helpful, 2=somewhat helpful, and $3=$ not helpful. The question for perceived fun was "Do you feel that Internet use gives you more fun, less fun, or no effect at all?" and the choices were $1=$ less fun, $2=$ no effect, and $3=$ more fun. The question for perceived interpersonal interaction was "Does the Internet allow you to interact with your friends and relatives more frequently, less frequently, or have no effect at all?" and the choices were $1=$ more frequently, $2=$ less frequently, and $3=$ no effect.

\section{Digital Opportunity}

"Digital opportunity" referred to whether the respondents felt any change or opportunities created from starting to use the Internet in their daily lives (eg, opportunities for employment and learning, or changes in their circle of friends or income). The study participants were asked if they had noticed any of the following changes: "Has your circle of friends / employment opportunity / learning opportunity / income / access to useful information / recreation and entertainment / government information increased because of your Internet use?" and "Is it possible for you to connect with others who share the same views in politics or policies?" (eight questions in total). The choices were $1=$ yes and $2=$ no.

\section{Information Literacy}

"Information literacy" referred to the basic capabilities that are required for Internet use (eg, becoming a member of specific website; downloading and uploading files, video clips, or photos). The study participants were asked, "Have you applied for user accounts and passwords and become a member of specific website?" and "Do you know how to download and upload files, video clips, or photos?" The choices were 1=yes and $2=$ no. They were also asked, "Are you familiar with any kind of word processing program (eg, Word, Notepad, or Writer) for document editing?" and the choices were 1=very familiar, $2=$ somewhat familiar, $3=$ not very familiar, and $4=$ no idea whatsoever. The distribution of information literacy was determined based on these categories.

\section{Statistical Analysis}

To examine the sociodemographic characteristics, opinions for Internet use, digital opportunity, and information literacy between participants with and without Internet adoption or withdrawal, $t$ tests and chi-square tests were used for the ordinal and nominal variables, respectively. Second, logistic regression analysis was employed to examine independent factors predicting Internet adoption and withdrawal with comparison to those individuals without adoption or withdrawal. Third, open data coding was carried out for the reasons for Internet adoption and withdrawal, with the results described using the frequency and percentage. We finally examined gender differences with regard to the aforementioned patterns, stratifying the analysis by gender.

\section{Results}

\section{Sociodemographic Characteristics and Opinions on Internet Use, Digital Opportunity, and Information Literacy}

The distribution of demographic characteristics and opinions about Internet use, digital opportunity, and information literacy of the participants with and without Internet adoption or withdrawal is presented in Table 1. Among the 1548 participants in 2007 , only $6.65 \%(n=103)$ adults belonged to the Internet adoption group (nonadopters: 1445/1548, 93.35\%). Among the 1575 adults in 2011 , only $18.60 \%(n=293)$ belonged to the Internet withdrawal group (nonwithdrawers: 1282/1575, $81.40 \%$ ). When it came to adopting the Internet, the factors of age, educational background, family income per month, and influence on life were significantly different between the adopters and nonadopters, whereas gender was not. Most of the Internet adopters had a high school or above diploma (89/103, $86.4 \%)$; nearly $60 \%(60 / 103)$ of the adopters had a family income of more than NT $\$ 30,000$ per month. Most of the adopters believed the Internet helped with their lives $(85 / 103$, $85.9 \%)$, and $60.2 \%(62 / 103)$ felt that it introduced more fun in their lives. 
Table 1. Sociodemographic characteristics, opinions on Internet use, digital opportunity, and information literacy between participants who did and did not adopt the Internet or withdraw from the Internet.

\begin{tabular}{|c|c|c|c|}
\hline Item by Internet adoption or withdrawal & Yes (adopted/withdrew) & No (did not adopt/withdraw) & $P$ \\
\hline Internet adoption & $\mathrm{N}=\mathbf{1 0 3}$ & $\mathrm{N}=1445$ & \\
\hline Age (years), mean (SD) & $58.4(6.0)$ & $65.2(9.6)$ & $<.001$ \\
\hline Gender (male), n (\%) & $54(52.4)$ & $681(47.1)$ & .30 \\
\hline Education, n (\%) & & & $<.001$ \\
\hline Elementary school or below & $14(13.6)$ & $1043(72.2)$ & \\
\hline High school & $66(64.1)$ & $333(23.1)$ & \\
\hline College or above & $23(22.3)$ & $69(4.8)$ & \\
\hline Family income/month (NT\$), n (\%) & & & $<.001$ \\
\hline$<30,000$ & $43(41.3)$ & $986(68.2)$ & \\
\hline $30,000 \sim 90,000$ & $45(44.0)$ & $384(26.6)$ & \\
\hline$>90,000$ & $15(14.7)$ & $75(5.2)$ & \\
\hline \multicolumn{4}{|l|}{ Opinions on Internet use, n (\%) } \\
\hline Perceived helpfulness & $85(85.9)$ & - & - \\
\hline Perceived fun & $62(60.2)$ & - & - \\
\hline Perceived more interpersonal interaction & $21(20.4)$ & - & - \\
\hline Internet withdrawal & $\mathrm{N}=\mathbf{2 9 3}$ & $\mathrm{N}=1282$ & \\
\hline Age (years), mean (SD) & $59.6(7.1)$ & $57.6(5.6)$ & $<.001$ \\
\hline Gender (male), n (\%) & $139(47.4)$ & $705(55.0)$ & .02 \\
\hline Education, n (\%) & & & $<.001$ \\
\hline Elementary school or below & $40(13.7)$ & $58(4.5)$ & \\
\hline High school & $173(58.9)$ & $524(40.9)$ & \\
\hline College or above & $80(27.4)$ & $700(54.6)$ & \\
\hline Family income/month (NT\$), n (\%) & & & $<.001$ \\
\hline$<30,000$ & $82(27.9)$ & $146(11.4)$ & \\
\hline $30,000 \sim 90,000$ & $152(52.1)$ & $563(43.9)$ & \\
\hline$>90,000$ & $59(20.0)$ & $573(44.7)$ & \\
\hline \multicolumn{4}{|l|}{ Digital opportunity, n (\%) } \\
\hline Larger circle of friends & $72(24.6)$ & $459(35.8)$ & .001 \\
\hline More job opportunities & $35(12.0)$ & $237(18.5)$ & .009 \\
\hline More learning opportunities & $123(41.8)$ & $948(73.9)$ & $<.001$ \\
\hline Increased income & $16(5.5)$ & $142(11.1)$ & .004 \\
\hline More information of life & $120(41.0)$ & $997(77.8)$ & $<.001$ \\
\hline Enriched recreation and entertainment & $114(39.0)$ & $914(71.3)$ & $<.001$ \\
\hline More government information & $90(30.7)$ & $761(59.4)$ & $<.001$ \\
\hline $\begin{array}{l}\text { Ability to connect with others with the same political/policy } \\
\text { views }\end{array}$ & $14(4.6)$ & $213(16.6)$ & $<.001$ \\
\hline \multicolumn{4}{|l|}{ Information literacy, n (\%) } \\
\hline Know how to apply for a user account and password & $52(17.8)$ & $705(55.0)$ & $<.001$ \\
\hline Know how to use a word processing program & $135(46.1)$ & $885(69.0)$ & $<.001$ \\
\hline Know how to upload and download files & $99(33.8)$ & $883(68.9)$ & $<.001$ \\
\hline
\end{tabular}

The analysis of Internet withdrawal shows that the factors of digital opportunity, and information literacy were significantly age, gender, educational background, family income per month, different between those who withdrew or did not, whereas where 
they lived did not. For the withdrawers, most were female $(154 / 293,52.6 \%)$ and $72.6 \%$ of them $(213 / 293)$ had a high school or lower diploma. Approximately $80 \%$ of the withdrawers (234/293) had a family income per month of NT $\$ 90,000$ or less. The top three digital opportunities that the nonwithdrawers had were Internet use helps with the "improved learning opportunity" (123/293, 41.8\%), followed by "more access to useful information" (120/293, 41.0\%), then "enriched recreation and entertainment" (114/293, 39.0\%). In addition, less than $50 \%$ of the withdrawers $(135 / 293,46.1 \%)$ selected "know how to use a word processing program (eg, Word or Notepad) for document editing" for their information literacy, whereas the percentage was greater than $50 \%$ for nonwithdrawers in all three categories of information literacy.

\section{Factors Predicting Internet Adoption and Withdrawal}

The results of the logistic regression analysis evaluating the independent effects of the demographic characteristics, opinions on Internet use, digital opportunity, and information literacy of the study participants on Internet adoption and withdrawal are presented in Table 2. For Internet adoption, the older the participants were, the less likely they were to experience adoption (OR 0.9, 95\% CI 0.92-0.9), and similar results for educational background, as those with less education had less adoption. For withdrawal, the Internet withdrawal risk was significantly lower for middle-aged and older adults who had a family income per month of NT $\$ 90,000$ or more (as opposed to those with NT $\$ 30,000$ or less; OR $0.4,95 \%$ CI 0.2-0.8), who felt enriched recreation and entertainment (OR 0.6, 95\% CI 0.4-0.9), access to more useful information (OR $0.5,95 \% \mathrm{CI}$ 0.3-0.9), knew how to apply for a user account and password (OR 0.4, 95\% CI 0.2-0.6), and how use a word processor (OR $0.6,95 \%$ CI 0.4-0.9). On the other hand, the risk of Internet withdrawal was significantly higher for those participants who were older (OR 1.1, 95\% CI 1.0-1.1).

Table 2. Factors predicting Internet adoption and withdrawal among middle-aged and older adults by logistic regression.

\begin{tabular}{|c|c|c|c|c|}
\hline \multirow[t]{2}{*}{ Factor } & \multicolumn{2}{|c|}{ Adoption (yes/no) } & \multicolumn{2}{|c|}{ Withdrawal (yes/no) } \\
\hline & OR $(95 \% \mathrm{CI})$ & $P$ & OR $(95 \% \mathrm{CI})$ & $P$ \\
\hline Age & $0.9(0.9-0.9)$ & .001 & $1.1(1.0-1.1)$ & .003 \\
\hline Gender (male/female) & $0.8(0.4-1.3)$ & .28 & $0.7(0.4-1.0)$ & .07 \\
\hline \multicolumn{5}{|l|}{ Educational background } \\
\hline College or above/elementary school or below & $19.4(7.9-47.1)$ & $<.001$ & $0.5(0.2-1.1)$ & .10 \\
\hline \multicolumn{5}{|l|}{ Family income/month (NT\$) } \\
\hline $30,000-90,000 /<30,000$ & $0.9(0.5-1.7)$ & .85 & $0.8(0.5-1.4)$ & .39 \\
\hline$>90,000 /<30,000$ & $1.0(0.4-2.4)$ & .10 & $0.4(0.2-0.8)$ & .008 \\
\hline larger circle of friends & - & - & $1.4(0.9-2.3)$ & .19 \\
\hline More job opportunities & - & - & $2.0(1.0-3.9)$ & .04 \\
\hline More learning opportunities & - & - & $0.8(0.5-1.3)$ & .31 \\
\hline Increased income & - & - & $0.5(0.2-1.4)$ & .17 \\
\hline More life information & - & - & $0.5(0.3-0.9)$ & .01 \\
\hline Enriched recreation and entertainment & - & - & $0.6(0.4-0.9)$ & .02 \\
\hline More government information & - & - & $0.8(0.5-1.2)$ & .28 \\
\hline Ability to connect with others who have the same political/policy views & - & - & $0.6(0.3-1.4)$ & .24 \\
\hline \multicolumn{5}{|l|}{ Information literacy (yes/no) } \\
\hline Know how to apply for a user account and password & - & - & $0.4(0.2-0.6)$ & $<.001$ \\
\hline Know how to upload and download files & - & - & $0.6(0.4-0.9)$ & .03 \\
\hline
\end{tabular}


Table 3. Reasons for Internet adoption and withdrawal for middle-aged and older adults.

\begin{tabular}{|c|c|}
\hline Type and item & $\mathrm{n}(\%)$ \\
\hline Internet adoption & $\mathrm{N}=94$ \\
\hline \multicolumn{2}{|l|}{ Needs $(66.0 \%)$} \\
\hline Job needs & $24(25.5)$ \\
\hline Keep up with the world & $38(40.4)$ \\
\hline \multicolumn{2}{|l|}{ Expansion of life (24.4\%) } \\
\hline Look for data and information & $9(9.6)$ \\
\hline Stock market & $6(6.4)$ \\
\hline Interested in learning & $4(4.3)$ \\
\hline Online ticket purchase & $2(2.1)$ \\
\hline Read news & $2(2.1)$ \\
\hline \multicolumn{2}{|l|}{ Recreation and entertainment $(9.6 \%)$} \\
\hline Play games and have fun & $4(4.3)$ \\
\hline Kill some time & $4(4.3)$ \\
\hline Watch TV online & $1(1.1)$ \\
\hline Internet withdrawal ${ }^{a}$ & $\mathrm{~N}=\mathbf{2 9 1}$ \\
\hline \multicolumn{2}{|l|}{ Health barriers (21.0\%) } \\
\hline I am old and my eyes or body has deteriorated & $48(16.5)$ \\
\hline I forgot how it works; it does not work well for me & $13(4.5)$ \\
\hline \multicolumn{2}{|l|}{ Psychological barriers (66.3\%) } \\
\hline I do not have the time & $128(44.0)$ \\
\hline It has no use for me & $53(18.2)$ \\
\hline Nothing worth watching/reading & $12(4.1)$ \\
\hline \multicolumn{2}{|l|}{ Equipment or environmental barriers (7.2\%) } \\
\hline The computer is out of order & $10(3.4)$ \\
\hline I do not have a computer or Internet access at home & $8(2.8)$ \\
\hline Internet access is too expensive & $1(0.3)$ \\
\hline Internet connection is poor & $1(0.3)$ \\
\hline Stop for home renovation & $1(0.3)$ \\
\hline \multicolumn{2}{|l|}{ Anthropic factor or accidental barriers $(5.5 \%)$} \\
\hline Others need the computer at home & $8(2.8)$ \\
\hline Travel to a foreign country or stay somewhere else for a period of time & $3(1.0)$ \\
\hline Family accident & $2(0.7)$ \\
\hline Internet access is canceled so that kids will not use it too much & $2(0.7)$ \\
\hline Retirement & $1(0.3)$ \\
\hline
\end{tabular}

${ }^{\text {a }}$ The sample size of Internet withdrawers was 293 adults and there were two with missing data; therefore, the final sample size of Internet withdrawers was 291 older adults.

\section{Reasons for Internet Adoption and Withdrawal}

Table 3 shows the results of the causes for middle-aged and older Internet adopters and withdrawers. For the reason of adoption, 66\% (62/94) of participants indicated they started using Internet "out of need," followed by "expansion of life" $(23 / 94,24.4 \%)$, and then "recreation and entertainment" (9/94, 9.6\%). Among "needs," "keep up with the world" (38/94,
$40.4 \%$ ) was listed as the most critical reason, followed by "job needs" $(24 / 94,25.5 \%)$. For the reason of withdrawal, the highest percentage went to "psychological barriers," such as having no time available, no meaningful use, or nothing worth reading/watching $(193 / 291,66.3 \%)$; followed by "health barriers" such as eyes or body deteriorating or do not work well enough to use the Internet (61/291, 21.0\%), "equipment barriers" 
such as having no computer or Internet access at home (21/291, $7.2 \%$ ), and "anthropic factor or accidental barriers" such as having no computer to use because others need it at home, or travel to a foreign country for a period of time $(16 / 291,5.5 \%)$.

\section{Gender Differences}

The results of the analysis for the reasons for Internet withdrawal among the middle-aged and older adults by gender are shown in Table 4. For the details of withdrawal reason, a large proportion of Internet withdrawals could be attributed to having no time available (males: 67/138, 44.7\%; females: 61/150, $44.2 \%$ ). However, for women the second most significant reason for withdrawal was "I am old and my eyes or body has deteriorated" (32/150, 21.3\%) and the third was "it has no use for me" $(21 / 150,14.0 \%)$. For men, the second most significant reason for withdrawal was "it has no use for me" (32/138,
$23.2 \%$ ) and the third was "I am old and my eyes or body has deteriorated" $(16 / 138,11.6 \%)$. For the category of withdrawal reason, the motivation for withdrawal was significantly more often due to anthropic factor or accidental barriers $(11 / 150$, $7.3 \%$ vs $4 / 138,2.9 \%, P=.02)$ or health barriers $(39 / 150,26.0 \%$ vs $22 / 138,16.0 \%, P=.004$ ) for women than for men. Moreover, despite the failure to reach statistical significance, men had more psychological and equipment-related barriers than women. Nevertheless, it was found that the psychological barriers were the most important factor influencing Internet withdrawal for both males and females. A total of $72.5 \%$ (100/138) males and $62.0 \%$ (93/150) females believed that their Internet withdrawal behaviors were associated with psychological factors such as having no time available, no meaningful use, or nothing worth watching/reading.

Table 4. Reasons for Internet withdrawal among middle-aged and older men $(n=138)$ and women $(n=150)$.

\begin{tabular}{|c|c|c|c|}
\hline Reason for Internet withdrawal & Men, n (\%) & Women, n (\%) & $P$ \\
\hline \multicolumn{4}{|l|}{ Reasons (by “details") } \\
\hline \multicolumn{4}{|l|}{ Health barriers } \\
\hline I am old and my eyes or body has deteriorated & $16(11.6)$ & $32(21.3)$ & .003 \\
\hline I forgot how it works; it does not work well for me & $6(4.4)$ & $7(4.7)$ & .52 \\
\hline \multicolumn{4}{|l|}{ Psychological barriers } \\
\hline I do not have the time & $61(44.2)$ & $67(44.7)$ & .11 \\
\hline It has no use for me & $32(23.2)$ & $21(14.0)$ & .44 \\
\hline Nothing worth watching/reading & $7(5.1)$ & $5(3.3)$ & .82 \\
\hline \multicolumn{4}{|l|}{ Equipment or environmental barriers } \\
\hline The computer is out of order & $6(4.4)$ & $4(2.7)$ & .75 \\
\hline I do not have a computer or Internet access at home & $5(3.6)$ & $3(2.0)$ & .67 \\
\hline Internet access is too expensive & $1(0.7)$ & $0(0.0)$ & .37 \\
\hline Internet connection is poor & $0(0.0)$ & $1(0.7)$ & .27 \\
\hline Stop for home renovation & $1(0.7)$ & $0(0.0)$ & .37 \\
\hline \multicolumn{4}{|l|}{ Anthropic factor or accidental barriers } \\
\hline Others need the computer at home & $1(0.7)$ & $7(4.7)$ & .02 \\
\hline Travel to a foreign country or stay at somewhere else for a period of time & $0(0.0)$ & $3(2.0)$ & .06 \\
\hline Family accident & $2(1.5)$ & $0(0.0)$ & .20 \\
\hline \multicolumn{4}{|l|}{ Reason (by “category”) } \\
\hline Health barriers & $22(16.0)$ & $39(26.0)$ & .004 \\
\hline Psychological barriers & $100(72.5)$ & $93(62.0)$ & .41 \\
\hline Equipment or environmental barriers & $12(8.7)$ & $7(4.7)$ & .53 \\
\hline Anthropic factor or accidental barriers & $4(2.9)$ & $11(7.3)$ & .02 \\
\hline
\end{tabular}

\section{Discussion}

This study is the first to use nationally representative data for older adults in Taiwan to examine the issues of Internet adoption and withdrawal. The results showed that both the respondents who adopted the Internet and with greater probability of continued use had the characteristics of higher proportion in men, younger and with higher education. In addition, the most important reasons for Internet adoption were associated with "needs," especially keeping up with the world and job needs. Furthermore, although psychological barriers were the most important factor of Internet withdrawal for both men and women, women were more likely to be affected by health and anthropic factors or accidental barriers in this regard. 
A number of factors associated with older adults' technology adoption have been documented in the literature [41,42], although the reasons behind these factors have rarely been examined. This study found that the main reasons why older adults may choose to use the Internet are associated with needs, especially with regard to keeping up with the world and job-related needs. In addition, if older adults think that using the Internet can increase their employment opportunities (OR $2.0,95 \%$ CI 1.0-3.9, $P=.04$ ), access to useful information (OR $0.5,95 \%$ CI $0.3-0.9, P=.01)$, and recreation and entertainment, then they are less likely to withdraw from using it. These findings echo previous research indicating that older adults who do not use new technology or learn new things may simply not see the need for much of what is being offered [43]. Education or training should be provided to help older adults understand the underlying structures and benefits of new learning opportunities.

Many of the existing studies focused on how deteriorating health conditions can hinder older adults' use of technology or learning efforts. Recent international studies also indicated that people tend to withdraw from the Internet due to health-related factors (eg, age-related changes in visual acuity, color perception and susceptibility to glare, and hearing problems) and some psychological barriers (eg, computer anxiety, online problems, and privacy issues) $[15,16,44-46]$. This study used a nationally representative sample and the results echo those of other recent works, showing that psychological barriers play the most important role in Internet withdrawal among middle-aged and older adults in Taiwan, followed by health factors. Moreover, it was surprising to find that most of the middle-aged and older adults in this study's data felt that "no available time" was the main reason that kept them from not using Internet. This suggests that elderly education should not only focus on health conditions because psychological factors may be critical to Internet usage and learning. For example, the selective optimization with compensation model of successful aging [47] may be useful in helping older adults to cope with the barriers they face when adopting new learning. Compensation reminds older adults to consider the reality of a person's capacities and the health barriers they face, selection refers to the ways older adults use to overcome such barriers, whereas optimization highlights the resources older adults have for achieving their goals.

Gender differences in Internet use have been documented in a number of studies, although in this study using Taiwanese data, men and women were not different in Internet adoption. However, they were different in Internet withdrawal, with men less likely to withdraw from Internet use than women were. In addition, for both men and women, the most common response for the reason for Internet withdrawal was for "psychological barriers" (eg, no time available, no meaningful use, or nothing worth reading/watching) followed by "health barriers" (eg, eyes or body deteriorating with Internet use). Although "psychological barriers" were the most important factor for Internet withdrawal among both men and women, women were more likely than men were to be affected by health and anthropic factors or accidental barriers. We suggest that in addition to focusing on health barriers, such as relearning to overcome cognitive declines, it is also important to work to reduce anthropic factors or accidental barriers, possibly by providing more resources, to encourage women to use new technology or take more learning opportunities.

This study has some limitations. First, this work was based on a cross-sectional survey and it may not be possible to draw any conclusions on the causal relationship between Internet user types and social engagement. Second, due to our data structure we only investigated Internet adoption and withdrawal behavior during 2007 and 2011. Given the rapidly changing nature of the Internet and technology adoption by older adults, we acknowledge that the dynamics of adoption and withdrawal may change over time. However, although the next generation of older adults will have extensive Internet experience, different problems and solutions may arise with regard to adoption and withdrawal behaviors due to the nature of the human learning process. Moreover, the rapid pace of technological change means that "future older generations" are likely to confront an array of technologies they little understand and generally find inaccessible. According to Hanson [48], understanding the general technology-related skills of older users, identifying the strategies successfully used by this population, and finding designs that are optimized for older adults' abilities (eg, life experiences and knowledge) are the most promising directions for research into technology or computer use by older adults. We believe that factors and reasons associated with Internet adoption and withdrawal found in this study can help to inform education or care for the elderly, a subpopulation that is not in the mainstream or main working force of a nation, and who have special needs associated with their physical and psychological degeneration. Third, due to the limitations of secondary data, this study only examined basic sociodemographic correlates. Various factors that may be related to Internet adoption or withdrawal, such as having a disability or living alone, should be examined in future research. Fourth, the definition of Internet withdrawal remains unclear in the literature. In this study, we defined it as if those participants with Internet experience had not used the Internet during the previous month. This definition is justified because, based on the cognitive competence and memory function of older adults, if such individuals do not use the Internet for one month, then their likelihood of doing so again decreases. However, the specific definition of Internet withdrawal among older adults used in the literature needs to be explored more in the future.

A critical role of technology as an important health promotion strategy for older adults in low- and middle-income countries has been proposed [49]. Our study on factors associated with Internet adoption and withdrawal provides a new lens that can help health educators to understand strategies that foster older adults in learning, an important element for active aging. Specifically, this study examining factors and reasons associated with Internet adoption and withdrawal from nationally representative data on middle-aged and older adults in Taiwan found that the learning motivation and learning models for older adults may not be different by gender, but to prevent withdrawal from learning by middle-aged and older adults, it is important that the approach be different by gender. With our findings that women were more likely to be affected by health and anthropic 
factors or accidental barriers, we suggest that in addition to focusing on health barriers, such as relearning to overcome cognitive declines, it is also important to work to reduce anthropic factors or accidental barriers, possibly by providing more resources, to encourage women to take more learning opportunities. In addition, for health educators to design courses and activities, it is essential that learning satisfies older adults' needs, such as keeping up with the world or job needs, such that they gain the knowledge and skills that could increase quality of life and assist them to transition into aging successfully.

\section{Acknowledgments}

This work was supported by grants from the Ministry of Science and Technology in Taiwan (MST103-2314-B-006-038-MY3).

\section{Conflicts of Interest}

None declared.

\section{References}

1. Cohen JE. Human population: the next half century. Science 2003 Nov 14;302(5648):1172-1175. [doi:

10.1126/science.1088665] [Medline: 14615528]

2. Vincent G, Velkoff V. The Next Four Decades. The Older Population in the United States: 2010 to 2050. Washington, DC: US Department of Commerce, Economics and Statistics Administration, US Census Bureau; 2010. URL: https://www. census.gov/prod/2010pubs/p25-1138.pdf [accessed 2017-10-30] [WebCite Cache ID 6ubUnaZXQ]

3. Fox S. Pew Research Center. 2011. Health topics URL: http://www.pewinternet.org/2011/02/01/health-topics-2/ [accessed 2017-10-23] [WebCite Cache ID 6uQLOHerY]

4. Levine DM, Lipsitz SR, Linder JA. Trends in seniors' use of digital health technology in the United States, 2011-2014. JAMA 2016 Aug 2;316(5):538-540. [doi: 10.1001/jama.2016.9124] [Medline: 27483069]

5. Shapira N, Barak A, Gal I. Promoting older adults' well-being through Internet training and use. Aging Ment Health 2007 Sep;11(5):477-484. [doi: 10.1080/13607860601086546] [Medline: 17882585$]$

6. Hogeboom DL, McDermott RJ, Perrin KM, Osman H, Bell-Ellison BA. Internet use and social networking among middle aged and older adults. Educ Gerontol 2010 Jan 05;36(2):93-111. [doi: 10.1080/03601270903058507]

7. Trocchia PJ, Janda S. A phenomenological investigation of Internet usage among older individuals. J Consum Mark 2000 Dec;17(7):605-616. [doi: 10.1108/07363760010357804]

8. Torres S. A culturally-relevant theoretical framework for the study of successful ageing. Ageing Soc 1999;19(1):33-51.

9. Nimrod G. The benefits of and constraints to participation in seniors' online communities. Leisure Stud 2012 Jul 12;33(3):247-266. [doi: 10.1080/02614367.2012.697697]

10. Berner J, Aartsen M, Wahlberg M, Elmståhl S, Berglund J, Anderberg P, et al. A cross-national and longitudinal study on predictors in starting and stopping Internet use (2001-2013) by Swedish and Dutch older adults 66 years and above. Gerontechnology 2016;14(3):157-168. [doi: 10.4017/gt.2016.14.3.012.00]

11. Lifshitz R, Nimrod G, Bachner YG. Internet use and well-being in later life: a functional approach. Aging Ment Health 2016 Sep 22:1-7. [doi: 10.1080/13607863.2016.1232370] [Medline: 27657190]

12. Friemel TN. The digital divide has grown old: determinants of a digital divide among seniors. New Media Soc 2014 Jun 12;18(2):313-331. [doi: 10.1177/1461444814538648]

13. Dove E, Astell A. The use of motion-based technology for people living with dementia or mild cognitive impairment: a literature review. J Med Internet Res 2017;19(1):e3. [doi: 10.2196/jmir.6518]

14. Cody MJ, Dunn D, Hoppin S, Wendt P. Silver surfers: training and evaluating internet use among older adult learners. Commun Educ 1999 Oct;48(4):269-286. [doi: 10.1080/03634529909379178]

15. Carpenter BD, Buday S. Computer use among older adults in a naturally occurring retirement community. Comput Hum Behav 2007 Nov;23(6):3012-3024. [doi: 10.1016/j.chb.2006.08.015]

16. Gatto SL, Tak SH. Computer, Internet, and e-mail use among older adults: benefits and barriers. Educ Gerontol 2008 Aug 22;34(9):800-811. [doi: 10.1080/03601270802243697]

17. Jelenchick LA, Eickhoff JC, Moreno MA. Facebook depression? Social networking site use and depression in older adolescents. J Adolesc Health 2013 Jan;52(1):128-130. [doi: 10.1016/j.jadohealth.2012.05.008] [Medline: 23260846]

18. Taha J, Sharit J, Czaja S. Use of and satisfaction with sources of health information among older Internet users and nonusers. Gerontologist 2009 Oct;49(5):663-673. [doi: 10.1093/geront/gnp058] [Medline: 19741112]

19. Oppenauer C. Motivation and needs for technology use in old age. Gerontechnology 2009;8(2):82. [doi: 10.4017/gt.2009.08.02.006.00]

20. Burnett JS, Mitzner TL, Charness N, Rogers WA. Understanding predictors of computer communication technology use by older adults. Hum Fac Erg Soc P 2011 Sep 01;55(1):172-176. [doi: 10.1177/1071181311551036]

21. Von Solms R, De Lange E. SenPortal: Internet-based services for senior citizens: case notes: building the information society. Afr J Info Comm 2013:76-81. 
22. Yu C. Computer and Internet Attitudes Among Ethnically Diverse Older Adults: A Path Analysis [master's thesis]. Northridge, CA: California State University, Northridge; 2012.

23. Choi NG, Dinitto DM. The digital divide among low-income homebound older adults: Internet use patterns, eHealth literacy, and attitudes toward computer/Internet use. J Med Internet Res 2013 May;15(5):e93 [FREE Full text] [doi: 10.2196/jmir.2645] [Medline: 23639979]

24. Werner JM, Carlson M, Jordan-Marsh M, Clark F. Predictors of computer use in community-dwelling, ethnically diverse older adults. Hum Factors 2011 Oct;53(5):431-447 [FREE Full text] [Medline: 22046718]

25. Kim KO. The Emotional Responses of Older Adults to New Technology [dissertation]. Urbana, IL: University of Illinois at Urbana-Champaign; 2012.

26. Adams N, Stubbs D, Woods V. Psychological barriers to Internet usage among older adults in the UK. Med Inform Internet Med 2005 Mar;30(1):3-17. [doi: 10.1080/14639230500066876] [Medline: 16036626]

27. Berner JS, Rennemark M, Jogréus C, Berglund J. Factors associated with change in Internet usage of Swedish older adults (2004-2010). Health Informatics J 2013 Jun;19(2):152-162. [doi: 10.1177/1460458212462151] [Medline: 23715214]

28. Wlodarczyk D, Chylińska J, Lazarewicz M, Rzadkiewicz M, Jaworski M, Adamus M, et al. Enhancing doctors' competencies in communication with and activation of older patients: the Promoting Active Aging (PRACTA) computer-based intervention study. J Med Internet Res 2017 Feb 22;19(2):e45 [FREE Full text] [doi: 10.2196/jmir.6948] [Medline: 28228370]

29. Knowles M. The Modern Practice of Adult Education. New York: New York Association Press; 1970.

30. Ashby L, Travis S. Teach yourself how to teach an older patient. RN 1988 Apr;51(4):25-28. [Medline: 3358067]

31. Simon SJ. The impact of culture and gender on web sites. SIGMIS Database 2001 Dec 31;32(1):18. [doi: $10.1145 / 506740.506744]$

32. Penard T, Poussing N, Mukoko B, Tamokwe Piaptie GB. Internet adoption and usage patterns in Africa: evidence from Cameroon. Technol Soc 2015 Aug;42:71-80. [doi: 10.1016/j.techsoc.2015.03.004]

33. Wasserman IM, Richmond-Abbott M. Gender and the Internet: causes of variation in access, level, and scope of use. Social Science Q 2005 Mar;86(1):252-270. [doi: 10.1111/j.0038-4941.2005.00301.x]

34. Degeratu AM, Rangaswamy A, Wu J. Consumer choice behavior in online and traditional supermarkets: the effects of brand name, price, and other search attributes. Int J Res Mark 2000 Mar;17(1):55-78. [doi: 10.1016/S0167-8116(00)00005-7]

35. Nayak LU, Priest L, White AP. An application of the technology acceptance model to the level of Internet usage by older adults. Univ Access Inf Soc 2010 Feb 16;9(4):367-374. [doi: 10.1007/s10209-009-0178-8]

36. Wood E, Lanuza C, Baciu I, MacKenzie M, Nosko A. Instructional styles, attitudes and experiences of seniors in computer workshops. Educ Gerontol 2010 Sep 07;36(10-11):834-857. [doi: 10.1080/03601271003723552]

37. Ramón-Jerónimo MA, Peral-Peral B, Arenas-Gaitán J. Elderly persons and Internet use. Soc Sci Comput Rev 2013 Feb 07;31(4):389-403. [doi: 10.1177/0894439312473421]

38. Hashmi N, Manzoor I, Naser F. Computer use in medical students. Computer 2012;78(18):22.

39. Buse CE. When you retire, does everything become leisure? Information and communication technology use and the work/leisure boundary in retirement. New Media Soc 2009 Oct 06;11(7):1143-1161. [doi: 10.1177/1461444809342052]

40. Chiu C, Hu Y, Lin D, Chang F, Chang C, Lai C. The attitudes, impact, and learning needs of older adults using apps on touchscreen mobile devices: results from a pilot study. Comput Hum Behav 2016 Oct;63:189-197. [doi: 10.1016/j.chb.2016.05.020]

41. Lee C, Myrick R, D'Ambrosio L, Coughlin J, de Weck OL. Older adults' experiences with technology: learning from their voices. In: Communications in Computer and Information Science. Berlin: Springer; 2013:251-255.

42. Lee C, Coughlin JF. PERSPECTIVE: Older adults' adoption of technology: an integrated approach to identifying determinants and barriers. J Prod Innov Manag 2014 Jun 03;32(5):747-759. [doi: 10.1111/jpim.12176]

43. Huber L, Watson C. Technology: education and training needs of older adults. Educ Gerontol 2013 Sep 06;40(1):16-25. [doi: 10.1080/03601277.2013.768064]

44. Charness N, Boot W. Aging and information technology use. Curr Dir Psychol Sci 2009 Oct;18(5):253-258. [doi: 10.1111/j.1467-8721.2009.01647.x]

45. Campbell R. Older women and the internet. J Women Aging 2004;16(1-2):161-174. [doi: $\underline{10.1300 / J 074 v 16 n 01 ~ 11] ~[M e d l i n e: ~}$ 15149930]

46. Becker SA. A study of web usability for older adults seeking online health resources. ACM Trans Comput-Hum Interact 2004 Dec 01;11(4):387-406. [doi: 10.1145/1035575.1035578]

47. Baltes BP, Baltes MM. Psychological perspectives on successful aging: the model of selective optimization with compensation. In: Baltes PB, Baltes MM, editors. Successful Aging: Perspectives From the Behavioral Sciences. Cambridge: Cambridge University Press; 1990:1-34.

48. Hanson V. Technology skill and age: what will be the same 20 years from now? Univ Access Inf Soc 2011 Apr 20;10(4):443-452. [doi: 10.1007/s10209-011-0224-1]

49. Kim J, Lee H, Christensen M, Merighi J. Technology access and use, and their associations with social engagement among older adults: do women and men differ? J Gerontol B Psychol Sci Soc Sci 2017 Sep 01;72(5):836-845. [doi: 10.1093/geronb/gbw123] [Medline: 28073816] 
Edited by G Eysenbach; submitted 24.01.17; peer-reviewed by D Tao, YH Chang; comments to author 05.06.17; revised version received 13.09.17; accepted 30.09.17; published 03.11 .17

Please cite as:

Chiu CJ, Liu CW

Understanding Older Adult's Technology Adoption and Withdrawal for Elderly Care and Education: Mixed Method Analysis from National Survey

J Med Internet Res 2017;19(11):e374

URL: http://www.jmir.org/2017/11/e374/

doi: 10.2196/jmir.7401

PMID: 29101093

(C)Ching-Ju Chiu, Chia-Wen Liu. Originally published in the Journal of Medical Internet Research (http://www.jmir.org), 03.11.2017. This is an open-access article distributed under the terms of the Creative Commons Attribution License (https://creativecommons.org/licenses/by/4.0/), which permits unrestricted use, distribution, and reproduction in any medium, provided the original work, first published in the Journal of Medical Internet Research, is properly cited. The complete bibliographic information, a link to the original publication on http://www.jmir.org/, as well as this copyright and license information must be included. 